\title{
IMPLEMENTATION OF 3D TOOLS AND IMMERSIVE EXPERIENCE INTERACTION FOR SUPPORTING LEARNING IN A LIBRARY-ARCHIVE ENVIRONMENT. VISIONS AND CHALLENGES.
}

\author{
Alexandra Angeletaki ${ }^{1}$, Marcello Carrozzino ${ }^{2}$, Stein Johansen $^{1}$ \\ ${ }^{1}$ Norwegian University of Science and Technology (NTNU) University Library, Gunnerus branch, \\ Trondheim, Norway \\ alexandra.angeletaki@ub.ntnu.no \\ ${ }^{2}$ PERCRO, TECIP Institute, Scuola Superiore Sant'Anna, Pisa, Italy \\ m.carrozzino@sssup.it
}

KEY WORDS: Archives, Augmented books, Immersive reality, 3D heritage, Participatory Education

\begin{abstract}
:
In this paper we present an experimental environment of 3D books combined with a game application that has been developed by a collaboration project between the Norwegian University of Science and Technology in Trondheim, Norway the NTNU University Library, and the Percro laboratory of Santa Anna University in Pisa, Italy. MUBIL is an international research project involving museums, libraries and ICT academy partners aiming to develop a consistent methodology enabling the use of Virtual Environments as a metaphor to present manuscripts content through the paradigms of interaction and immersion, evaluating different possible alternatives. This paper presents the results of the application of two prototypes of books augmented with the use of XVR and IL technology. We explore immersive-reality design strategies in archive and library contexts for attracting new users. Our newly established Mubil-lab has invited school classes to test the books augmented with 3D models and other multimedia content in order to investigate whether the immersion in such environments can create wider engagement and support learning. The metaphor of 3D books and game designs in a combination allows the digital books to be handled through a tactile experience and substitute the physical browsing. In this paper we present some preliminary results about the enrichment of the user experience in such environment.
\end{abstract}

\section{INTRODUCTION}

Contemporary libraries increasingly engage software engineers and computer scientists to create technical solutions for the digitization of their archives. The digitization of collections is used as a preservation method (Tonta, 2008) even though the validity, the resistance duration and the archiving is discussed as a risk component. Some libraries have been engaging in emerging technologies as augmented reality (Kalay, Kvan, \& Affleck, 2007) to make information content more attractive and accessible to a broader public. The questions are many to keep in mind and will even multiply as new technologies emerge and create a challenge for the traditional notions of how cultural heritage is presented and interpreted by todays contemporary professionals (Kalay et al., 2007). The main question this paper wishes to draw on is whether the introduction of virtual and immersive technologies in disseminating the contents of a library-archive collection can enrich the contemporary perception about libraries.

\section{RELATED WORK}

The idea of applying 3D technology for promoting the collections of archives and libraries is not new (Almeida, Cubaud, Dupire, Natkin, \& Topol, 2006) and the investigation of its influence on the visitor experience has created new possibilities for books to be handled as digital representations rather than physical fragile objects (Grasset, Dunser, \& Billinghurst, 2008). Models of evaluation methodology, needs further development. Research in the field has been borrowing ethnographic and phenomenological tools or usability analysis methods(Bowman, 2005) to evaluate the learning outcome of the visitor experience in an immersive environments. A series of projects claim that most computer applications create digital involvement by active participation, and enhance learning through a cognitive dialogue with the user (Styliani, 2009). Archive collections materialize a new existence through the digitalization process. The books and manuscripts presented as digital representation acquire a new character. Furthermore, through the use of augmented reality, they become disseminated for larger groups of users. Libraries and archives have become virtual destinations (Anunobi \& Okoye, 2008) in our technologically rich age. The visitor`s experience then becomes a type of social interaction in a computer mediated environment (Galani, 2003). The questions to be raised are many, since no conceptual model has been developed for augmented reality books that contain 3D virtual and animated content and little research has been done on the evaluation of such designs (Grasset et al., 2008).

\section{THE SYSTEM DESIGN}

MUBIL, uses novel technologies to present manuscripts and old books from the historical archives of the NTNU University Library. Its main purpose was to create a 3D laboratory and a space of interactive immersion at the 
library to support learning. Museums, libraries and ICT academy partners are involved in order to develop a consistent methodology enabling the use of Virtual Environments as a metaphor to present manuscripts content through the paradigms of interaction and immersion (Carrozzino 2013), evaluating different possible alternatives. Our main research interest is thus to explore how visitors interact with the historical collections of our library in an interactive immersive virtual environment. Two books were chosen for this experiment and they are presented here. Two 3D book prototypes are presented here. The first one is a treatise on distillation of medicinal plants written in 1590 ? by Adam Lonicer called "Kreuterbuch". The second one is a manuscript about a travel of a noble Norwegian in 1768 . Hans Hansen Lilienskiold travelled through Europe with his brother to get an education, as this was the habit of the nobilities of that time.

\subsection{The technological platform}

Augmented books: The technological tool we use to promote archive content in this study is $3 \mathrm{D}$ technology, where the user interacts with objects virtually rendered in an immersive reality environment. Manuscripts are presented in the form of an interactive 3D book (augmented book). Users can freely explore the original pages of the book or access their translations into several languages. An enhanced interaction modality enables the exploration of additional content purposely developed for the project such as 3D texts, images, movies, audios, and real-time animated 3D models. In Figure 1, a page from the 3D transposition of Lonicer's treatise on medical distillation is presented.

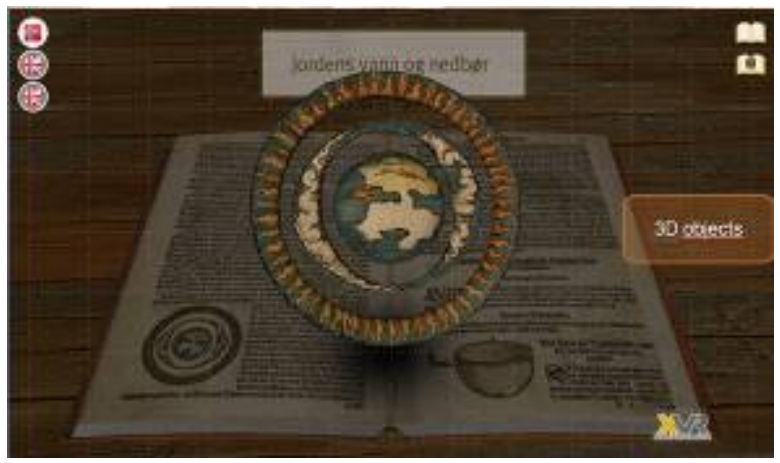

Fig. 1: Augmented book

An alternate representation of manuscripts is based on the Information Landscape metaphor (Ruffaldi et al., 2008). ILs are Virtual Environments not corresponding to any real environment, where the three-dimensional space is used as a context to map semantic relationships among the elements, and therefore the layout itself acts as a source of information. This concept has been applied to a second manuscript of the Gunnerus Library collection, a travel journal by Lilienskiold. The derived IL has been centered on the metaphor of the trip to Italy and in particular to Pisa, acting as an ideal bridge between the two countries involved in the MUBIL project. Section of the texts are distributed onto a Virtual Environment representing a stylized 3D map of Pisa, loosely based on the one realized in (Carrozzino, 2013), where the major monuments, described by the author, are visually highlighted. Other information layers are represented by audio narration, explanatory movies and a glossary.

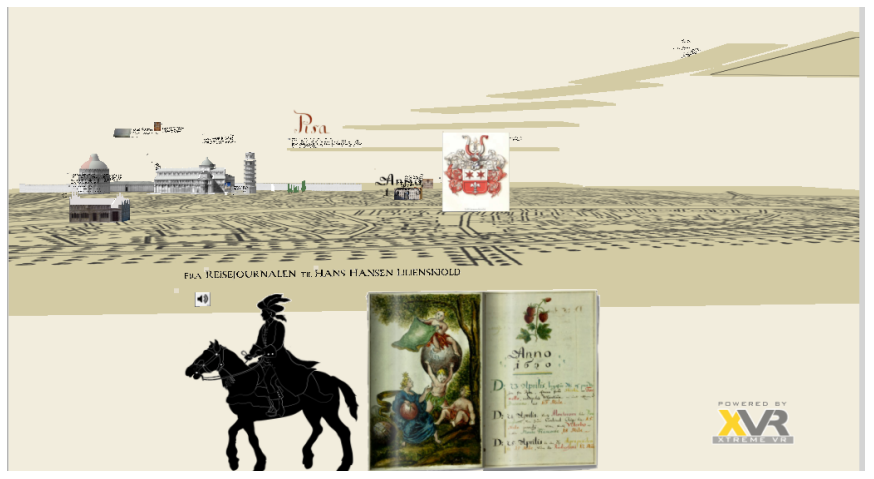

Fig. 7: Lilienskiold Information Landscape

The aim of an IL is not to exactly represent the reality, but rather to go with the user through a path of knowledge inside a completely abstract world. Inside an IL, information is presented in a layout commonly designed to present semantic significance, allowing the user for an immediate interpretation of the presented concept. The IL is conceived to bring users directly inside the information, so that their learning originates from their exploration of that world.

User interaction with the landscape can be completely free or take place through a constraint navigation activated by links, which allow readers to follow a predefined interpretation of the logical structure of information.

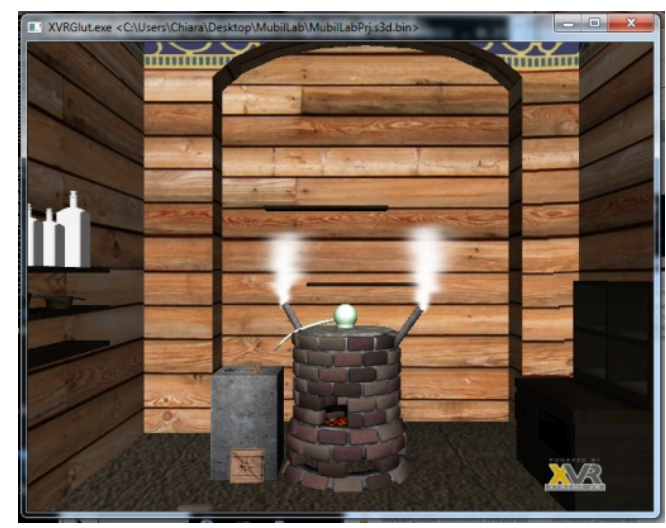

Fig. 3: The Alchemy lab.

A third interaction level is represented by the Virtual Laboratory, an application meant to connect the previous levels and allow readers to exploit the knowledge acquired in the previous levels. The reader becomes an apprentice alchemist that must perform a real experiment based on the distillation notions acquired from the Lonicer treatise and on other information provided by Lilienskiold's book. A point-and-click interaction metaphor enables players to discover information, combine objects and perform all the operations involved in the distillation of a medicine. Thanks to the flexibility of the application architecture and of the XVR underlying technology (Tecchia et al., 2009), several interaction metaphors have been implemented based on different 
devices (mouse, joystick, Microsoft Kinect etc.). The same applies to visualization metaphors adapting to tablets, notebooks, and even immersive visualization systems such as CAVE. These two books have been used in a pilot project of outreach activities where we invite new user groups to our library. The alchemist lab experiment was presented to a school class as a field trip prepared by their teacher and the Mubil lab team. The teacher prepared chemistry assignments and the visit was embedded in their curriculum. Students participated in seeking knowledge tasks in a hybrid environment. A focus group was selected as our expert group and will come back to the lab in 2014. Their interviews help us establish an understanding of the elements that support learning through such an experimental frame (Hedstrom, 2002; Hein, 1998) .

\section{DISCUSSION}

A visit in such an archive environment is defined here as a learning experience that occurs in the context of participatory interaction (Simon, 2010). In our research we focus on the process of experiencing such environments in archives and examine the aspects of increased interaction and social participation. We adhere to the constructivist approach, which suggests that the knowledge of the past can be understood through the visitor's experience and on the visitor's premises rather than that of a powerful truth imposed by a public institution and its experts (Eberbach \& Crowley, 2005; Hein, 1998). Material things present themselves in relation to human beings (Hooper-Greenhill, 2000) either physical or virtual. They materialize themselves in the cognitive process of the learning intention (Flower \& Hayes, 1981) that the user carries when he enters the meaning-sphere of the object to be handled. Understanding how learning occurs in an immersive environment and try to measure the effect the virtual application has on the users is a demanding task for researchers (Roussou 2004). In our quest we have engaged the users, that is the school children that have visited our lab and have used the pilot applications to give us feedback on their experience. We asked them to evaluate the design, the graphics and the interactive design and let us know what was according to their experience and knowledge on what were the weaknesses and strengths of such interaction. We have looked into the video recordings and their user behavior and tried to identify the process of social conduct and collaborative production of meaning as others have done before (Galani 2004, Von Lehn 2002). We are at the beginning of our study and intend to organize further testing of the final applications and look into the details of communication and action between people, between people and objects and between people and learning environments (Goldman 2007, von Lehn 2002). We intend to use both video and sound recordings to collect primary material during all the successive visits. We believe that this method together with videography as an analysis tool will serve our purposes in the given context of mixed environments. Then a transcription system will be used based on the methods conversation analysis uses to analyze the cognitive process of actions and interaction (Heath 1986; Kendon 1990). That is we will look into the video recordings as a conversation between the objects, the tasks, the people, and the ICT content and reconstruct its development step by step in sequential frames. In collecting and analyzing the data of the visitors' experience, of the virtual objects the study will be adapting and enriching the "Interactive experience model" introduced by Falk $(1992,5)$ in Museum Science studies. The visitor's experience and his behavior as he interacts with the objects will be the observation field of the research. The new element of the visitors experience in our study is the practical engagement of free choice in tasks of interactive character in an immersive environment. The conceptual model used in the study is borrowed from the so called "enactive Knowledge" and refers to knowledge gained through a perception-action interaction" (Bergamasso, 2006) with the object itself. This kind of knowledge is supposed to be direct and personal based on the experience one gains through multi-modal tasks connected to exploit the particular object. Random interviews will be also used together with surveys pre- and post- tests in order to collect secondary data. A mixed method of both quantitative and qualitative methods will be applied for the analysis of the secondary data. The overall study will be drawing empirical data from a combined fieldwork. Ethical issues of visitor participation will be cleared up in advance with all the participants so that a protocol will be signed by all as to the use of the material for research purposes. The possibilities of interactive implementation of the XVR and IL software might be limited. The fact that this is a 3D tool not tailored for complex interactive design carries unpredictable technical implementation problems that appear along the way. Hopefully this kind of research in solving these kinds of technological challenges will contribute to new knowledge and will allow us to have an insight in the development and application of such tools. 3D technology evolves in a very rapid rhythm and new open source software as Unity and Oculus technology or the Google glasses appear on the market. That will definitely create rapid development of game and film applications. Our economic situation does not allow us to compete with such industries. Using 3D tools for such a purpose is not easy because besides visualization devices to showcase $3 \mathrm{D}$ content, we need to develop conceptual models of using the game tools so that we can explore, challenge and foster social participation. In order to examine the impact of such Lab design the project will be evaluated by neutral partners and random young users during 2014.

\section{CONCLUSIONS}

The idea of applying 3D technology for promoting the collections of archives and libraries is not new and the investigation of its influence on the visitor experience has created new possibilities for books to be handled as digital representations rather than physical fragile objects. In our paper we propose that there are several aspects of the immersive experience that such a tool allows us to investigate. We present here the preliminary results of a case study of a 3D lab where users interact with 3D virtual images of physical objects, as old manuscripts and books and their content, in a learning frame. By creating an interactive learning space in the library with the use of immersive reality tools we believe that we can enhance 
cultural understanding of historical archive collections. The introduction of novel technological tools in archive lab design creates a room for active participatory interaction space between the collections and the users. We intend to collect data of visitor interaction and try to contribute to the scholarly debate of digital technologies research used in humanities.

\section{AKNOWLEDGMENTS}

We would like to thank the National library of Norway for the financial support of our project and Professor Letizia Jaccheri from NTNU, IDI for her support and supervision. We must also thank all our collaborators for their dedication to our work. We also thank Daniele Duranti and Emanuele Ruffaldi for their fundamental contribution in the realization of the Information Landscape engine and authoring system.

See our website:

(http://www.ntnu.no/ub/omubit/bibliotekene/gunnerus$\underline{1 / \text { mubil). }}$. 


\section{REFERENCES}

Almeida, Rodrigo, Cubaud, Pierre, Dupire, Jérôme, Natkin, Stéphane, \& Topol, Alexandre. (2006). Experiments towards 3D immersive interaction for digital libraries Technologies for E-Learning and Digital Entertainment (pp. 1348-1357): Springer.

Anunobi, Chinwe V, \& Okoye, Ifeyinwa B. (2008). The role of academic libraries in universal access to print and electronic resources in the developing countries. Library Philosophy and Practice (e-journal), 189.

Bergamasso, M. (2006). Enactive network of Excellence, digest 2006. Lucca: Tipografia Francesconi.

Carrozzino, M., Bergamasco, M., Beyond virtual museums: Experiencing immersive virtual reality in real museums, Journal of Cultural Heritage 11 (4) , pp. $452-458$ (2010)

Carrozzino, M., Angeletaki, A., Evangelista, C., Lorenzini, C., Tecchia, F., Bergamasco, M., Virtual technologies to enable novel methods of access to library archives, SCIRES-IT, Vol 3, Issue 1 (2013), 25-34,

e-ISSN 2239-4303, DOI 10.2423/i22394303v3n1p25, CASPUR-CIBER Publishing (2013)

Bowman, Doug A. (2005). 3D user interfaces : theory and practice. Boston: Addison-Wesley.

Eberbach, Catherine, \& Crowley, Kevin. (2005). From Living to Virtual: Learning from Museum Objects. Curator: The Museum Journal, 48(3), 317-338. doi: 10.1111/j.2151-6952.2005.tb00175.x

Flower, Linda, \& Hayes, John R. (1981). A cognitive process theory of writing. College composition and communication, $32(4), 365-387$.

Galani, Areti. (2003). Mixed Reality Museum Visits: Using new technologies to support co-visiting for local and remote visitors. Museological review, 10.

Grasset, Raphael, Dunser, Andreas, \& Billinghurst, Mark. (2008). The design of a mixed-reality book: Is it still a real book? Paper presented at the Mixed and Augmented Reality, 2008. ISMAR 2008. 7th IEEE/ACM International Symposium on.

Hedstrom, M. (2002). Archives, memory, and interfaces with the past. Archival Science, 2(1-2), 21.

Hein, G., E. (1998). Learning in the museum. London ; New York: Routledge.

Hooper-Greenhill, Eilean. (2000). Museums and the interpretation of visual culture. London: Routledge.

Kalay, Yehuda, Kvan, Thomas, \& Affleck, Jane. (2007). New Heritage New Media and Cultural Heritage. From http://public.eblib.com/EBLPublic/PublicView.do?ptiID=325247

Simon, Nina. (2010). The participatory museum. Santa Cruz, Calif.: Museum 2.0.

Styliani, S. (2009). Virtual museums, a survey and some issues for consideration. Journal of cultural Heritage, 10(4), 520 528.

Ruffaldi, E., Carrozzino, M., Evangelista, C., Bergamasco, M., Neri, V., Design of information landscapes for cultural heritage content, Proceedings - 3rd International Conference on Digital Interactive Media in Entertainment and Arts, DIMEA 2008 , pp. 113-119 (2008)

Tecchia F., Carrozzino M.., Bacinelli S., Rossi F., Vercelli D., Marino G., Gasparello P., Bergamasco M., A Flexible Framework for Wide-Spectrum VR Development, Presence-Teleoperators And Virtual Environments; N. 19; $302: 312$ (2010)

Tonta, Y. (2008). Libraries and Museums in the Flat World: Are They Becoming Virtual Destinations? , from http://eprints.rclis.org/14035/ 